\title{
Finite Elements Modeling of Linear Motor for Automatic Sliding Door Application
}

\author{
Aymen Lachheb \\ Research Unit of Mechatronic \\ Systems and Signals \\ National Engineering School of \\ Carthage
}

Rue des entrepreneurs, 2035, Tunis

\author{
Lilia El Amraoui \\ Research Unit of Mechatronic \\ Systems and Signals \\ National Engineering School of \\ Carthage \\ Rue des entrepreneurs, 2035, Tunis
}

\author{
Jalel Khedhiri \\ Unit Signal, Image and Intelligent \\ Control of Industrial \\ System (SICISI) \\ National Engineering School of \\ Tunis
}

\begin{abstract}
In this paper, a linear switched reluctance motor is designed and investigated to be used as a sliding door drive system. A non linear two dimensions finite model is built to predict the performance of the designed motor. Thus, the static electromagnetic characteristics are investigated and analyzed. The inductance and the electromagnetic force are determined for different translator position and current intensities with consideration of magnetic saturation effects. The results of analysis prove that the magnetic behavior of this motor is non linear. Furthermore, an important asymmetry of the static and dynamic characteristics between the extreme phases and the central phase is observed in high excitation levels.
\end{abstract}

Keywords-linear motor; sliding door; 2D-finite-element analysis; switched reluctance

\section{INTRODUCTION}

Recently, linear motors are widely used in a large number of applications and have become more and more used in many areas, particularly in industries such as transportation, manufacturing, and robotics [1-3]. Contrary to the conventional systems where the linear movement is obtained by coupling a rotary motor to a ball screw system, the linear motor allows a direct linear drive without using rotary to linear transmission system. Then, it has fewer moving parts so low inertia. Furthermore, the use of linear motors is recommended for applications which require high speed and accuracy [4], with this technology the load is connected directly to the motor due to the absence of transmission systems which results in high performance capabilities and excellent dynamic characteristic. Because of these merits and benefits, linear motor has been increasingly studied in recent years [3], [5], [6], [7].

In reference [6], a vertical propulsion actuator system of a ship elevator with Linear Switched Reluctance Machine (LSRM) is designed and compared to traditional systems.

The design of electromechanical devices requires accurate prediction of the developed forces. In fact, these forces are derived from field solutions obtained by numerical computational methods. Several methods are in use, but some of them seem to be able to produce consistently accurate results. The advantages and disadvantages of each method are discussed in [8], [9].

Various methods have been reported in many work to predict the distribution of the magnetic field of electromagnetic structures, as the method of reluctance networks, the analytical method [5-6], 2D finite element [7], and 3D finite elements [8]. In this paper, a 2D finite element method is used to study the performances of switched reluctance linear motor.

Generally the classic automatic door opening is equipped with rotary motor and transmission systems. In such systems, the number of moving parts is important that can increase the possibilities of failures and has negative effects on the system dynamic and reliability [10].

To improve the performances and reduce the cost of the sliding door systems, a linear motor is proposed to compete the classical systems.

The first part of this paper is dedicated to the sizing of switched reluctance linear motor suitable for sliding door application. In fact, the main dimension and motor specifications are described.

Part II is reserved for the modeling of the linear motor using analytical method. This model can express the principles of electromechanical conversion governing the operation of a linear actuator with switched reluctance, as analytical relation with the assumption of the non-linearity of the used materials.

In part III, a 2D finite element (FE) model was developed to study the electromagnetic characteristics, the 2D FE model used to analyze and investigate the static behavior of the linear motor. The numerical solution of the developed model leads to compute the magnetic vector potential at each step displacement and to predict the magnetic field density and the magnetic force.

The developed mechanical model given by the classical motion equation is solved by using a numerical transient solver to obtain the dynamic characteristics. Then, the results obtained by the two dimensions finite element method analysis are presented. Finally, part V describes the conclusion of the work.

\section{SIZING OF THE SWITCHED RELUCTANCE LINEAR MOTOR}

The device to be studied in this work for sliding door application is a linear planar structure with three phases (A, B, C). It is composed of two ferromagnetic parts, the stator is an equidistant toothed bar and the translator which is the moving part of the motor. 
The proposed motor has an active translator (with a coil), it's composed of three modules separated by a nonmagnetic part, and each module represents a phase and contain two coils in series.

The design of the linear motor required careful analysis of the required specifications, the studied motor provide a bidirectional force that moves a sliding door which have a weight of $20 \mathrm{Kg}$.

Fig.1 shows the structure and winding diagram of the designed motor.

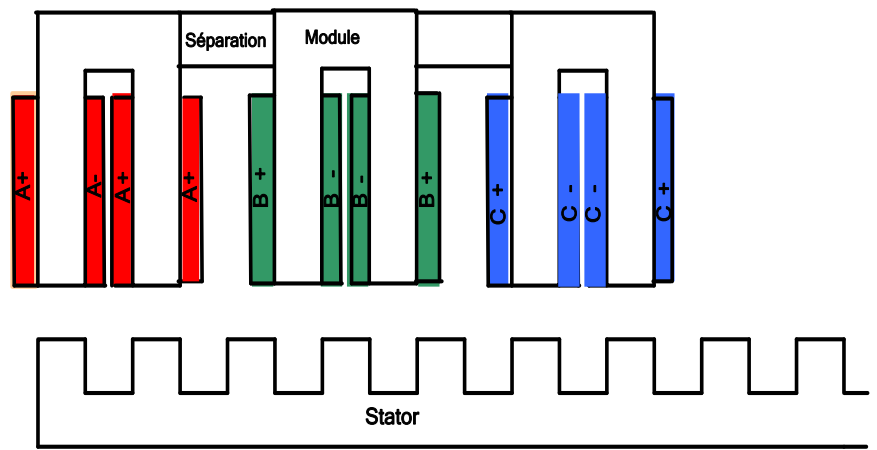

Fig. 1. Linear motor configuration and winding diagram

The choice of the width of the teeth of the motor as well as at the translator and stator must absolutely ensure the reversibility and regularity of motion.

This is guaranteed by the choice of pole pitch equal on the translator and the stator. Furthermore, the widths of teeth and slots for the translator and the stator should be equal, [5].

Indeed, the inequality of widths of teeth and pole pitch at the stator and mobile modules creates steps permeance around the equilibrium position, which induce a dead zone on the static force characteristics on which the movable part can move freely, Fig.2.

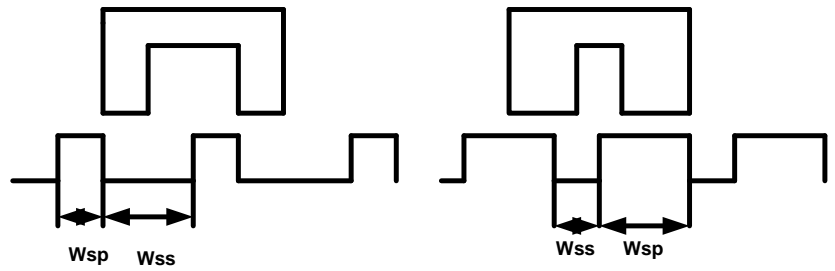

Fig. 2. Two elementary module configuration

The pole width and slot width are related to the pole pitch by the following equation:

$$
\lambda=w_{t s}+w_{t p}
$$

Where $w_{t s}$ is translator slot width, $w_{t p}$ is translator pole width.

The mover part includes three similar module shifted by a non magnetic separation has a width determinate by (2), [8].

$$
c=c_{0}+k \lambda
$$

The mechanical step $\delta_{\mathrm{m}}$ is related to the pole pitch and the number of phases by (3).

$$
\delta_{m}=\left|c_{0}-w_{s s}\right|=\frac{\lambda}{n}
$$

The yoke thickness in the stator and in the translator is choosing equal to the slot width.

$$
C_{s y}=C_{t y}=w_{t s}
$$

The Fig.3 present a half cross of the studied motor

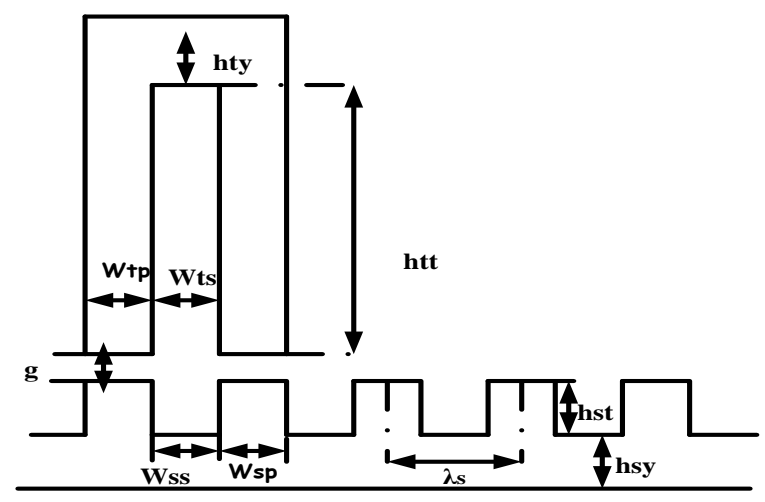

Fig. 3. Half Cross Section of the motor

The most significant geometry of the translator and stator are cited in the Table I:

TABLE I. SPECIFICATIONS OF DESIGNED MOTOR

\begin{tabular}{|l|l|l|l|}
\hline & Parameters & Symbols & Values \\
\hline \multirow{5}{*}{ Stator } & Teeth width & $\boldsymbol{w}_{s p}$ & $30 \mathrm{~mm}$ \\
\cline { 2 - 4 } & Slots width & $\boldsymbol{w}_{s s}$ & $30 \mathrm{~mm}$ \\
\cline { 2 - 4 } & Teeth high & $\boldsymbol{h}_{s t}$ & $30 \mathrm{~mm}$ \\
\cline { 2 - 4 } & Yocke thikness & $C_{s y}$ & $30 \mathrm{~mm}$ \\
\hline \multirow{5}{*}{ Translator } & Teeth width & $\boldsymbol{w}_{t p}$ & $30 \mathrm{~mm}$ \\
\cline { 2 - 4 } & Slots width & $\boldsymbol{w}_{t s}$ & $30 \mathrm{~mm}$ \\
\cline { 2 - 4 } & Teeth high & $\boldsymbol{h}_{t t}$ & $150 \mathrm{~mm}$ \\
\cline { 2 - 4 } & Yocke thikness & $\boldsymbol{C}_{t y}$ & $30 \mathrm{~mm}$ \\
\hline \multirow{4}{*}{ Coil } & Number of turn & $\boldsymbol{N}_{c}$ & 450 \\
\cline { 2 - 4 } & Section of copper & $\boldsymbol{S}_{c}$ & $0.5 \mathrm{~mm}$ \\
\hline \multirow{5}{*}{ Separation } & Width of separation & $C$ & $50 \mathrm{~mm}$ \\
\hline & Air gap & $g$ & $0.5 \mathrm{~mm}$ \\
\hline
\end{tabular}

\section{LINEAR MOTOR MODELING}

The linear motor model is done in two stages, the first stage describes the electromagnetic equations, in the second stage the mechanical equations is developed.

\section{A. Electromagnetic Equations}

By neglegting the phase mutual effect, the phase voltage of the linear motor is related to the flux linked in the winding by Faraday's law as : 


$$
U=R i+\frac{d \phi(x, i)}{d t}
$$

Where $i$ is the phase current, $U$ is the terminal voltage , $R$ is the phase winding resistance and $\phi$ is the flux linkage.

The flux linkage in a linear motor phase varies as a function of the phase current and translator position, thus

$$
U=R i+\frac{\partial \phi}{\partial i} \cdot \frac{\partial i}{\partial t}+\frac{\partial \phi}{\partial x} \cdot \frac{\partial x}{\partial t}
$$

The relation between flux and inductance is defined as follows:

$$
\phi(x, i)=L(x, i) i
$$

The characteristics of flux and inductance are determined by the $2 \mathrm{D}$ finite element method which will be presented subsequently.

In general, the thrust force produced by the linear motors, derived from coenergy.

When one phase is excited the electromagnetic force is written as follows:

$$
F_{x}=\frac{\partial W c(i, x)}{\partial x}\lfloor i=c t e
$$

The coenergy of each phase can be calculated in terms of flux linkage.

$$
W c(i, x)=\int_{0}^{i} \phi(i, x) d i
$$

\section{B. Mechanical Equation}

The mechanical equation of the drive system is obtained by the Newton equation given by the following equation:

$$
m \frac{d^{2} x}{d^{2} t}=F_{x}-F_{c}-f_{0} \operatorname{sign}\left(\frac{d x}{d t}\right)-\xi \frac{d x}{d t}
$$

Where:

$F_{x}:$ electromagnetic force $(\mathrm{N})$

$\frac{d x}{d t}:$ linear speed $(\mathrm{m} / \mathrm{s})$

$m$ : moving part and load weight $(\mathrm{Kg})$,

$F_{c}:$ the load force $(\mathrm{N})$

$f_{0}:$ the dray coefficient

$\xi \quad$ : viscosity coefficient (N.s/m)

\section{2-D Finite ElEMENT ANALYSIS (FEA)}

FEA is widely used to determine the performance of designed machine and allows to provide an accurate characteristic prediction.

In this work, a 2D FEA is used to predict the static and the dynamic response of the studied motor.

\section{A. Static characterization}

A FE model is developed to study the static behavior of the proposed motor. In fact, a complete configuration of the FE model obtained by using motor specification is shown in Fig.4.

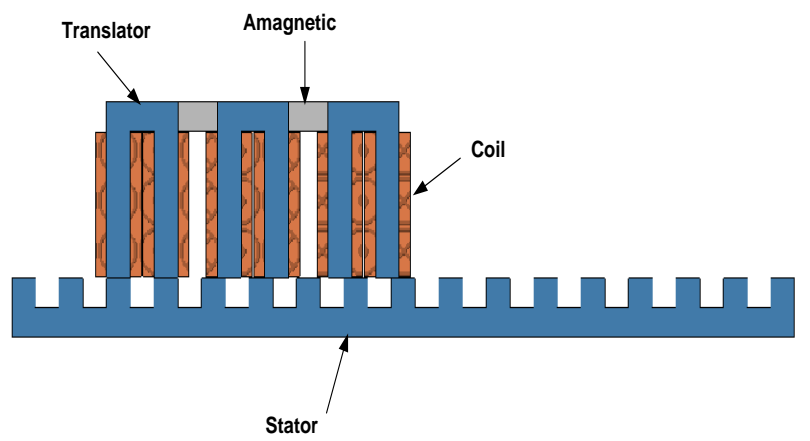

Fig. 4. Linear planner motor with modular configuration

The proposed structure of three phase motor, having a movable armature suspended over a fixed stator. The translator consists of three similar modules with six poles having command coils, and each module has two poles and has the same pole pitch.

The three modules are spaced so that only two poles at a time can be aligned with the poles of the stator. Non-magnetic separations are necessary between the various modules in order to impose a regular shift.

The windings of the electric circuit are laminated with copper and they are concentrated around the pole of each module, the coils of a same phase are connected in series.

The used material to manufacture the stator and translator is a 1010 steel, the corresponding magnetization curve of the last material is shown in Fig.5.

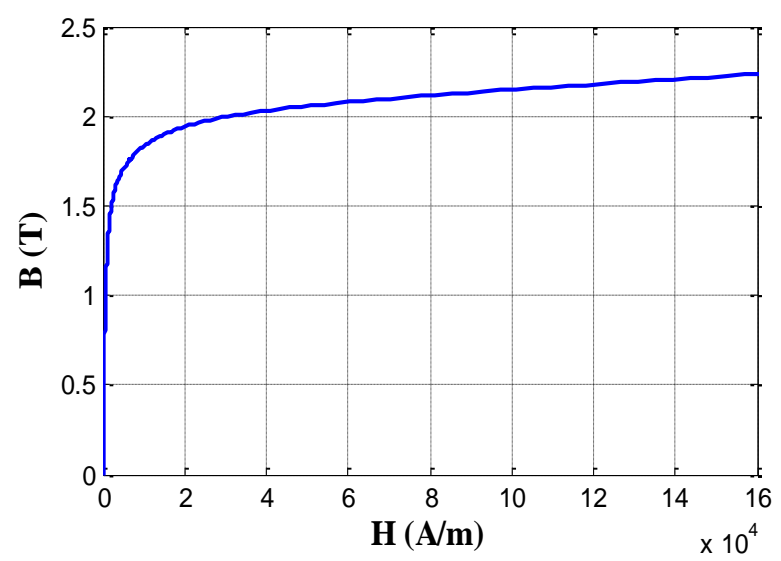

Fig. 5. The B-H curve of ferromagnetic material (1010 Steel)

This curve has three distinct regions, the steep initial part of the curve where a small increase in $\mathrm{H}$ produces a large increase in $\mathrm{B}$, the knee of the curve and the saturated region beyond the knee where a large increase in $\mathrm{H}$ implies a small increase in $\mathrm{B}$.

It can be observed from Fig .5, that a flux density about $2 \mathrm{~T}$ marks the onset of saturation in the used material. 
The design of many electromichanical devices requires the accurate prediction of the developed force.

In fact, the designed structure of the proposed linear motor was analyzed by use of 2D non linear FEA, then, a series of simulations is done by a 2D static solver in order to compute the electromagnetic force and flux linkage values for different translation position over one electric period. The obtained computed force as function of the translator positions is presented in Fig. 6 and Fig.7 for two case phases excitations of 1200AT, 3000AT respectively.

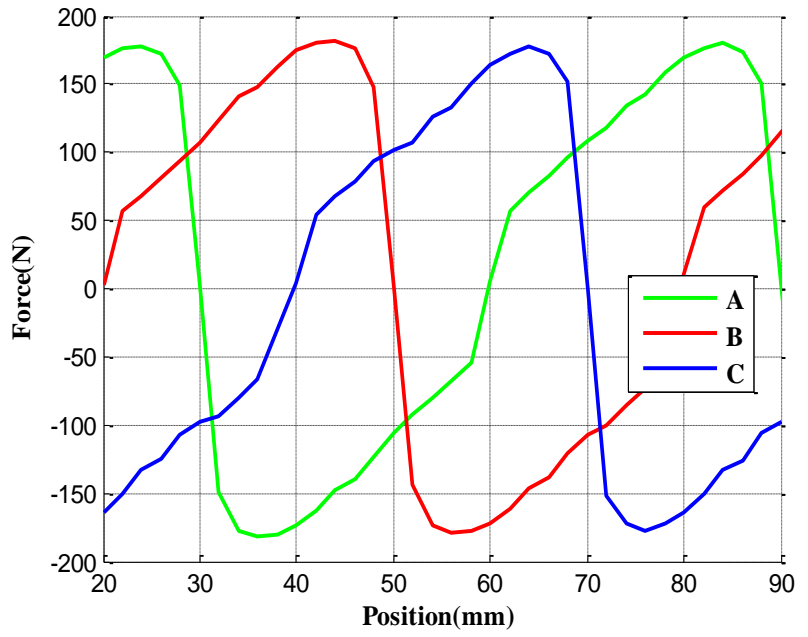

Fig. 6. Developed forces phases excited by 1200AT

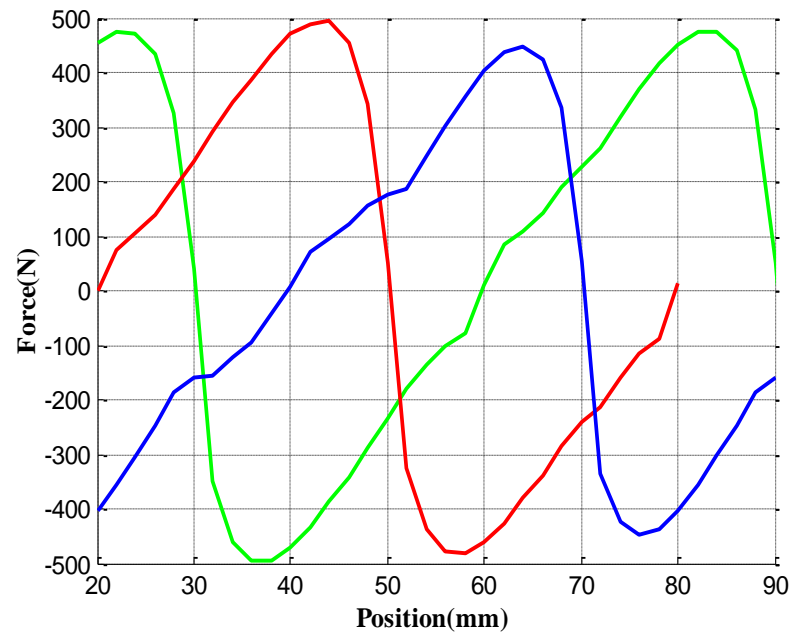

Fig. 7. Developed forces phases excited by 3000AT

The developed forces showed in Fig.6 and Fig.7 indicates that there is significant dissymmetry between the extremes and the central phase. At a current excitation about 3000Atrs, the extrem phase generates a maximum force of $500 \mathrm{~N}$, while the central phase develops a maximum force not exceeding $450 \mathrm{~N}$. It's clear that the end effect occurs for high values of excitation.

The magnetic flux path and magnetic field density are presented in the figures below when the three phases A,B,C successively excited by 3000AT. The distribution of the flux in the motor allows us to specify the degree of magnetic saturation in the different parts of a machine as well as the ratio of useful to leakage flux throughout the magnetic circuits.

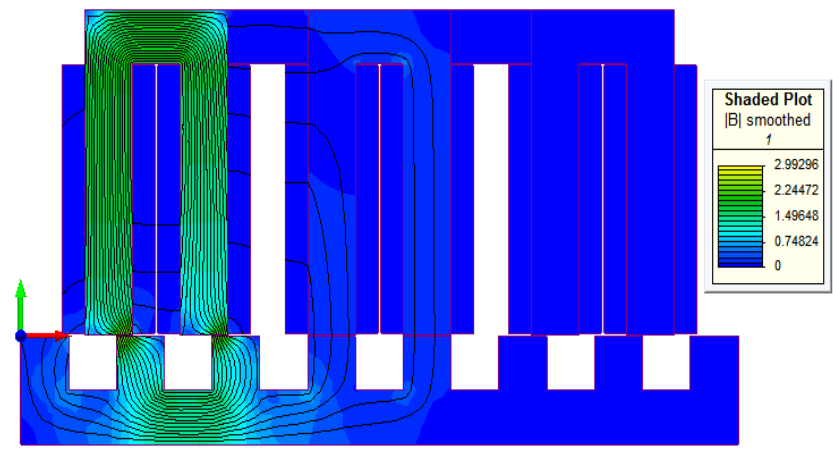

a) Flux distribution and field density when phase $\mathrm{A}$ is supplied by $3000 \mathrm{AT}$

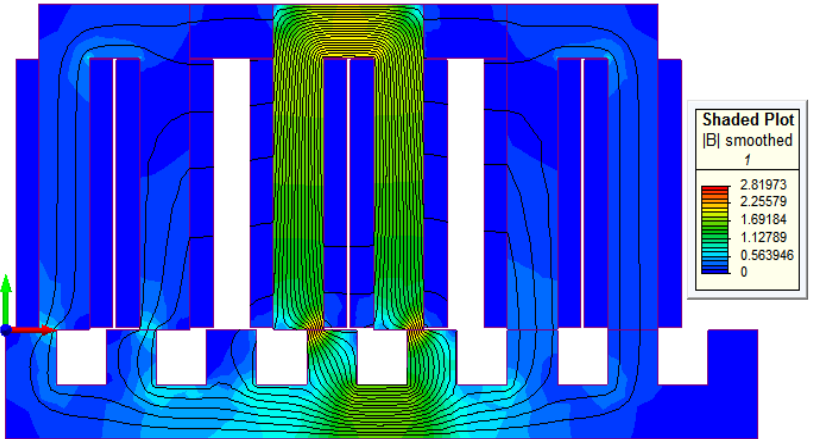

b) Flux distribution and field density when phase B is supplied by 3000AT

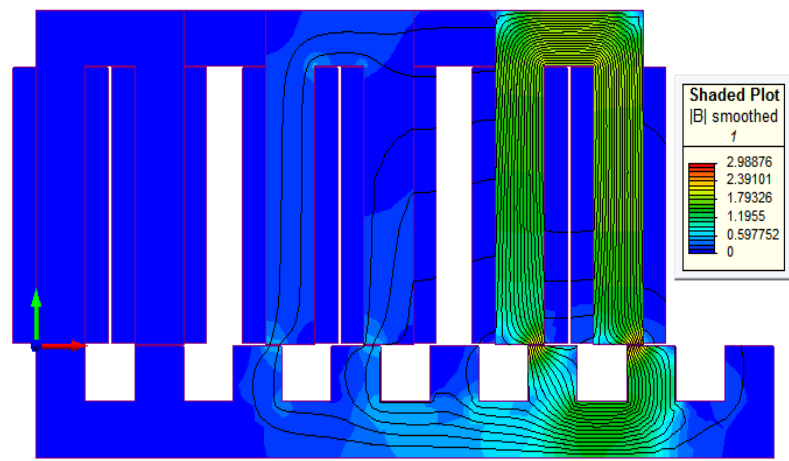

c) Flux distribution and field density when phase $\mathrm{C}$ is supplied by $3000 \mathrm{AT}$

Fig. 8. Distrubition of line flux through different phases

The analysis of the magnetic flux distribution for the same supplied current, confirm that a magnetic dissymmetries between the extreme phases and the phase in the center due to magnetic leakages.

The magnetic leakage in the central phase is more important than the extrem phases due to the leakage flux circulating through neighboring modules despite that there is a non-magnetic separator between them. Therefore, this magnetic losses creates a parasitic forces that affect the performance of the machine.

It can be seen from Fig.8, that when the field current is $3000 \mathrm{AT}$, the magnetic saturation arises in the pole tips of the 
stator and the translator. However, the pole bodies are not saturated.

The static characteristics of the linear machine are represented by the flux linkage variation with phase ampere turn and translator position.

Figure 9 illustrates a magnetization curve which is a plot of a flux linkage versus Ampersturn at three positions. These curves correspond respectively to the aligned, intermediaries, and unaligned position. The obtained flux curves as a function of the ampere turn are non linear and confirm the saturation of the used material for high values of current excitation.

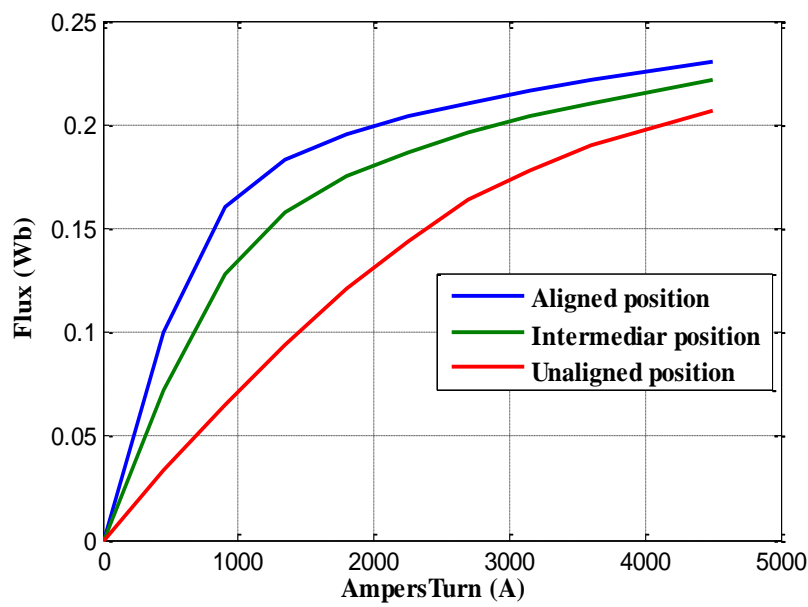

Fig. 9. Flux linkage as a function of ampere turn and translator position

In order to determine the profile of the inductance resorted the flux linkage equation given by (7).

The graphic in figure 10 shows the curves of inductance with the translator position for different magneto-motive force values between 600AT to 3000AT, where the translator is moved from an aligned position to an unaligned position.

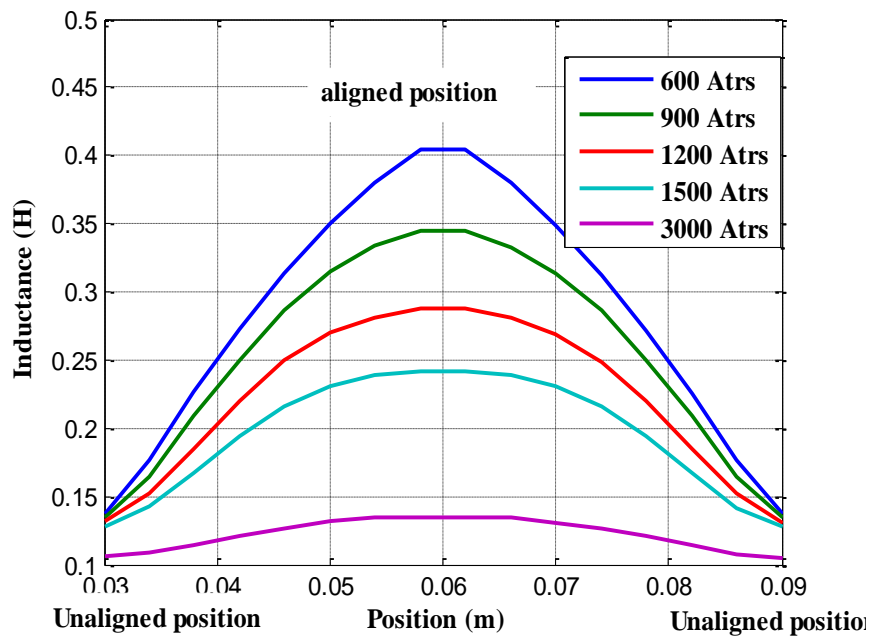

Fig. 10. Inductance-ampere turn characteristics

The obtained results show that the phase inductance in a LSRM is a periodic function of the translator position, the inductances curves are characterised by a maximum and a minimum value, these two values correspond in fact to the aligned and unaligned positions.

The results show at a given translator position, the phase inductance decreases with the applied phase current because of magnetic saturation.

The phase inductance at the aligned position varies considerably with the supplied current. However, the unaligned inductance does not very much changed, mainly because of the large reluctance that characterizes wide air gap in the flux path.

\section{B. Dynamic response}

The proposed linear motor is designed for direct drive system. Thus, it's important to study the dynamic behavior. In this topic, a model was developed by FE method and was used to predict the dynamic behavior of the proposed motor.

In this work, a coupled electromagnetic-mechanical model for transient analysis of linear motor has been described, the mechanical parameters of the proposed structure are: $m=20 \mathrm{Kg}, \xi=65 \mathrm{~N} . \mathrm{s} / \mathrm{m}, f_{0}=0.1 \mathrm{~N}$.

The simulation of the dynamic of the motor is done according to the synopsis schema bellow.

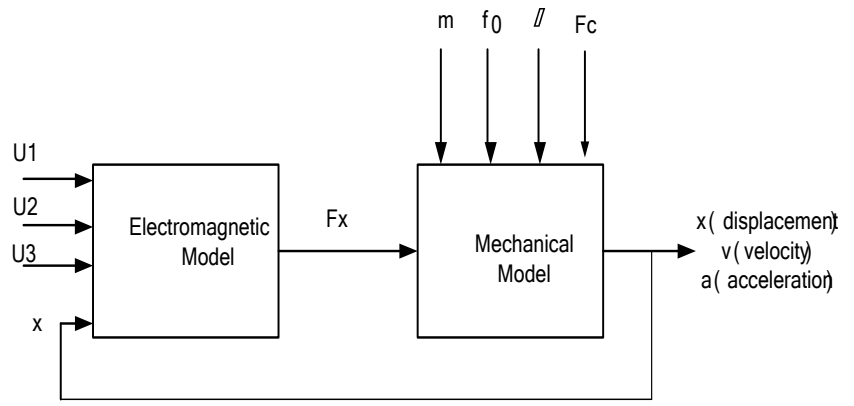

Fig. 11. Synopsis diagrame

In the following, we present the performances of the motor obtained by transient analysis FEM .The dynamic responses obtained are shown in Fig12-15.

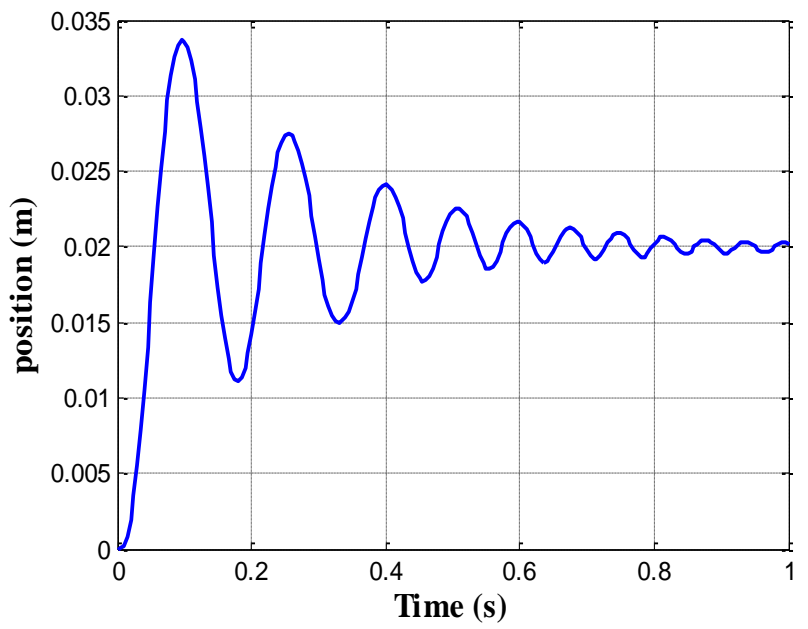

Fig. 12. Displacement versus time 
The computed displacement versus time is obtained when the coil is excited by 900Atrs, the movable part being initially shifted from $-20 \mathrm{~mm}$ relative to the aligned position, when a single phase is excited, the translator should move one step and stop at the position (stable equilibrium position).

The characteristic of displacement presents some oscillations around its balance position which is equal to $20 \mathrm{~mm}$ corresponding to the elementary step displacement of the designed motor.

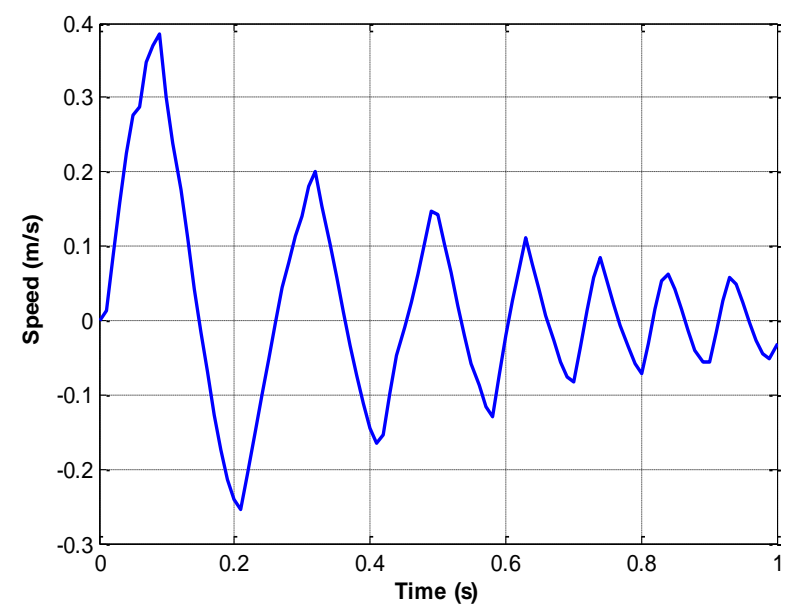

Fig. 13. Velocity versus time

In Fig.13 the moving part starts from the zero velocity to reach a maximum of $0.38 \mathrm{~m} / \mathrm{s}$ then it tends to the zero value at $1 \mathrm{~s}$ where the translator reaching the rest position.

One can observe from Fig. 13 that the velocity of the motor is characterized by a strong oscillation and great over shoot.

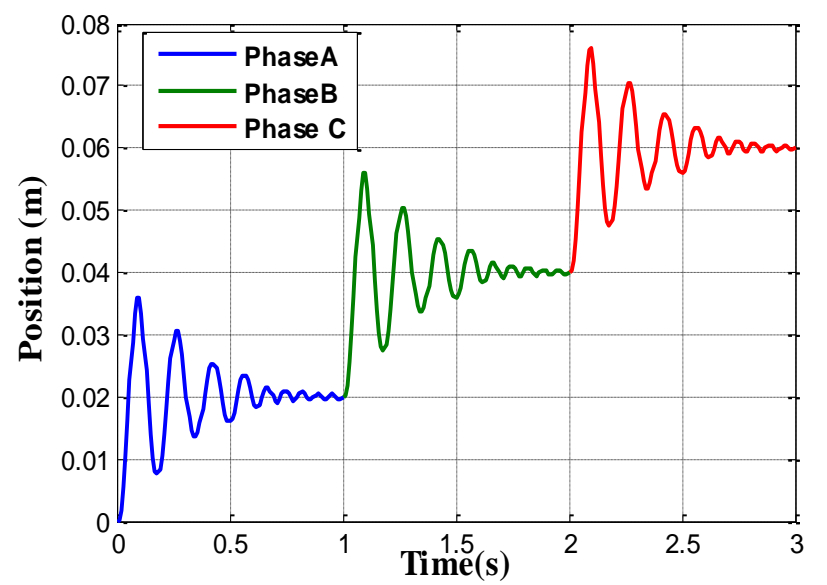

a) Suppliyed current 900 Atrs

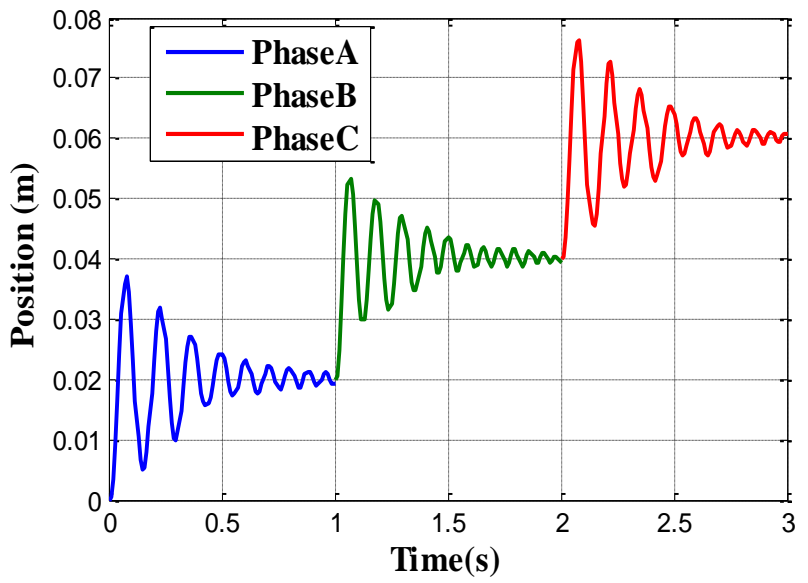

b) Suppliyed current 3000 Atrs

Fig. 14. Dynamic response of motor on three steps for two different currents

The displacement curve showed in Fig. 14 is obtained for two excitations current values corresponding to a linear region of magnetization curve and saturation region.

The obtained results indicate that the working in 3 successive mechanical steps without a load when only one phase is excited for a constant period. The period of each step is 1 second.

Also, the presented result shows at the first time phase A was excited allowing moving the translator on the first equilibrium position corresponding to $20 \mathrm{~mm}$ after that the phase $\mathrm{B}$, and $\mathrm{C}$ must be excited successively to obtain the other equilibrium position.

Fig 14.b show that the overshoots and the response of the system is increasing with the increase of the current excitation and an asymmetry appears between the external phases and central phase responses.

Fig.15 illustrate the characteristic of displacement when the phase $\mathrm{A}$ is excited with taking into account the effect of the load. When a load force is applied to the system, the equilibrium position of the linear motor is affected an error, it is shown that the displacement is accompanied by a great error with high value of load force.

These phenomena affect the position accuracy may cause loss of synchronization at high speed. To overcome such problems a logic control technique is necessary. 


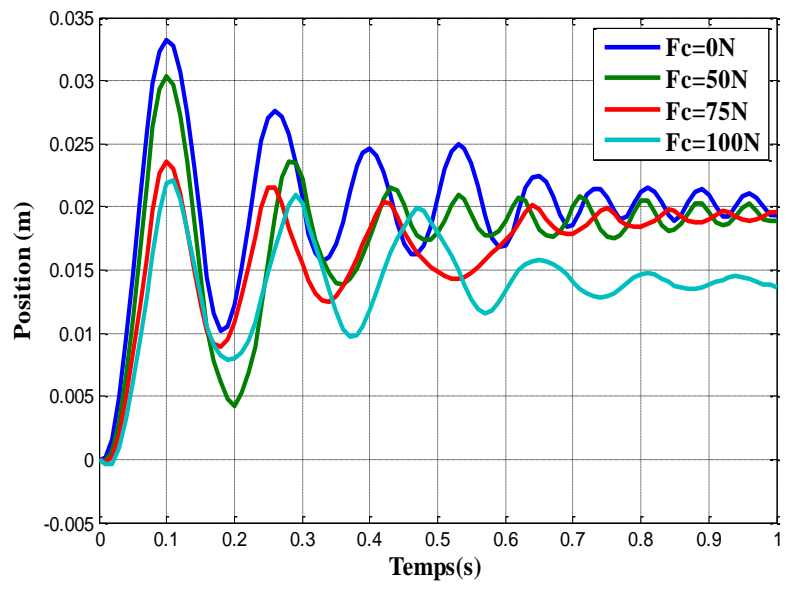

Fig. 15. Displacements versus time for different loads force

\section{CONCLUSION}

In order to improve the performance of the classical sliding door systems, a linear motor has been proposed. In this paper, an approach for linear switched reluctance sizing and design has been presented. For that reason, a model is developed by finite element method to calculate the static field and electromagnetic force produced by the chosen structure.

In addition, a FE analysis was performed on a basic pattern using nonlinear magnetic materials taking into account the saturation effects. The flux linkage and inductance characteristics are presented and discussed according to translator position and current. The obtained results show the presence of an important asymmetry and magnetic leakage between the motor phases in high excitation levels.

Based on the finite element method, the dynamic characteristics such as the displacement and the velocity are obtained. Then, the effect of the load in position is analysed, it was found that the variation of these parameters affects the positioning accuracy of the linear motor.

In the future research an optimal control strategy must be elaborated to reduce the significant oscillation of the motor and to improve its performance.

\section{REFERENCES}

[1] N.S.Lobo, Hong Sun Lim R..Krishnan, "Comparison of linear switched reluctance machines for vertical propulsion application: Analysis, design, and experimental correlation," IEEE Transactions on industry applications, Vol.44, No.4, August 2008.

[2] Lorand Szabo,Dan-Cristian Popa,Vasile Iancu "Compact double sided modular linear motor for narrow industria appications,"Power Electronics and Motion, Conference IEEE,2006.

[3] F.Daldaban, N.Ustkoyuncu "A novel linear switched reluctance motor for railway transportation systems, " Energy Conversation and Management,2010.

[4] Lilia El Amraoui, “ Conception electromagnétique d'une gamme d'actionneur Linéaire Tubulaire à Réluctance variable, " Thèse Doctorat en Génie Electrique, Ecole Centrale de Lille, 2002.
[5] L. El Amraoui ,F.Gillon ,"Performance estimation of linear tubular actuator," Conferences maglev, 2002.

[6] Hong Sun Lim , Hong Sun Lim, "Design and Control of a Linear Propulsion System for an Elevator Using Linear Switched Reluctance Motor Drives, " IEEE transactions on industrial electronics, Vol. 55, No. 2, February 2008.

[7] Byeong Seok Lee, Han Kyundg Bae, Praveen Vijayraghavan,R.krishnan, "Design of a linear Switched Reluctance Machine," IEEE Transaction on industry application ,1999.

[8] El Amraoui, GILLON F, Brochet P,BENREJEB M, "Design of a linear tubular step motor," Electromotion01,4th International symposium on Advanced Elecromechanical Motion Systems, vol.1 pp.223-228.

[9] Mokrani Lakhdar ,Contribution à la CAO optimisee des machines electriques , application au moteur linéaire à induction, " thèse doctorat en Electrotechnique, Faculté des sciences de l'ingénieur de Batna ,2005.

[10] M. Dursum, F. Koc, H.Ozbay, "Determination of geometric dimensions of a double sided linear switched reluctance motor, "World Academy of Science Engineering and Technology, 46,2010.

[11] Zaafrane Wajdi, khediri Jalel, Rehaoulia Habib , "Comparative design and modeling study of single sided linear planner switched reluctance motor," Wseas transactions on circuit and systems , volume 13,2014.

[12] J. G. Amoros , P. Andrada , "Sensitivity Analysis of Geometrical Parameters on a Double-Sided Linear Switched Reluctance Motor," IEEE Transactions on Industrial Electronics, VOL. 57, NO. 1, January 2010.

[13] Khidiri Jalel , "Alimentation et commande d'un actionnaire linéaire triphasé à flux transversale, " Thèse de Docteur Ingénieur en Génie Electrique,Université des Science et Technique de Lille FlandresArtois, 1986.

[14] Zaafrane Wajdi , Khidiri Jalel, Rehaoulia Habib, "2-D finite element design of a single sided linear planner switched reluctance motor," World Applied Sciences Journal , 25 (3): 494-499, 2013.

[15] Ge Baoming, Anibal T.de Almeida, "Design of Transverse Flux Linear Switched Reluctance Motor, "IEEE transaction on magnetics, Vol. 45, No. 1, January 2009.

[16] Ruiwu Cao, Ming Cheng, Chris Mi, "A linear doubly salient permanent magnet motor with modular and complementary structure," IEEE transaction on magnetics, Vol.47,No.12,December 2011.

[17] S.Taghipour Boroujeni, J.Milimonfared,"Design prototyping and analysis of a novel tubular permanent magnet linear machine, " IEEE transaction on magnetics, Vol.45,No.12,December 2009.

[18] M. Jufer, “ Traité d'éléctricité, éléctromécanique,” traité d'éléctricité, éléctromécanique", Presses Polytechniques et Universitaires romndes, Lausanne 1995.

[19] T.J.E.Miller, "Optimal design of switched reluctance Motos, " IEEE Trans.Ind, Electron, Vol.49, no.1,pp.15-27,Feb.2002.

[20] R.Krishnan,R.Arumugam, and J.F.Lindsay, "Design procedure for switched reluctance motors," IEEE Trans. Ind. Appl, Vol.24,no.3, pp.456-461, May/Jun.1988.

[21] H.S.Lim and R. krishnan, " Ropless elevator with linear switched reluctance motor drive actuation systems," IEEE Trans, Ind , Elecron , Vol .55 no.2,pp.534-542, Feb.2008.

[22] N.S. Lobo, H.S.Lim, a,d R.krishnan, "Comparaison of linear switched reluctance machines for vertical propulsion application Analysis, design and experimental correlation," IEEE Trans. Appl, Vol.44, no.4,pp.11341142, Jul/Aug.2008.

[23] P.K ,Budig, "The application of linear motors ," In Proc.3rd IEEE Int.Power Electron.and Motion Contorl Conf.Aug. 2000,vol.3,pp 13361341. 